\title{
Conservación de vegetación para reducir riesgos hidrometereológicos en una metrópoli fronteriza
}

\section{Vegetation conservation to reduce hidrometeorological risks on a border metropoli}

Yazmin Ochoa González ${ }^{a^{*}}$ (i) (http:// orcid.org/0000-0002-8441-7668)
Lina Ojeda-Revah ${ }^{\mathrm{a}}$ (i) (http:// orcid.org/0000-0001-6006-8128)

${ }^{a}$ El Colegio de la Frontera Norte, Departamento de Estudios Urbanos y del Medio Ambiente, Tijuana, Baja California, México, correos electrónicos: yochoa@colef.mx, lojeda@colef.mx

\section{Resumen}

El cambio de uso del suelo afecta la dinámica del paisaje especialmente en las ciudades, lo que incrementa el riesgo ante eventos meteorológicos extremos y reduce la capacidad de resiliencia. La Zona Metropolitana de Tijuana-Tecate-Rosarito, con topografía accidentada, pocas áreas verdes, alta biodiversidad y endemismos, presenta riesgos de deslaves e inundaciones. Se propone crear infraestructura verde (red de áreas verdes) sobre pendientes pronunciadas, cursos de agua y áreas con biodiversidad especial. Con estas va-

Recibido el 8 de julio de 2015. Aceptado el 19 de enero de 2016.

*Autor para correspondencia: Yazmin Ochoa González, correo electrónico: yochoa@colef.mx

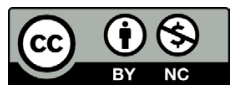

Todos los contenidos de Estudios Fronterizos se publican bajo la licencia Creative Commons Atribución no comercial 2.5 México, y pueden ser usados gratuitamente para fines no comerciales, dando el crédito a los autores y a la revista Estudios Fronterizos. riables e imágenes de satélite se construyeron mapas de usos del suelo y vegetación y escenarios de conservación, se analizó su conectividad y su factibilidad legal. Gran parte de la vegetación con alta conectividad se conserva solo cumpliendo la legislación de no construir en áreas de riesgo. Al sumar las áreas con biodiversidad especial, aumenta la superficie a conservar y su conectividad. Sin embargo, la legislación existente no es suficiente, está dispersa o no se aplica.

Palabras clave: infraestructura verde, servicios ecosistémicos, riesgos, zona metropolitana, Tijuana.

\section{Abstract}

Land cover change affects landscape dynamics, especially in big cities, which leads to increased risks when extreme meteorological events occurs and reduces resilience capacity. The Tijuana-Tecate-Rosarito metropolitan area, characterized by a rough topography, lack of green areas, high biodiversity and endemism, is prone to landslide and floods risks. To solve these problems, this study proposes a green infrastructure plan (interconnected green areas). Based on the construction of a land use-cover map using satellite im-

CÓMO CITAR: Ochoa, Y. y Ojeda-Revah, L. (2017). Conservación de vegetación para reducir riesgos hidrometereológicos en una metrópoli fronteriza [Vegetation conservation to reduce hidrometeorological risks on a border metropoli]. Estudios Fronterizos, 18(35), 47-69, doi: 10.21670/ref.2017.35.a03 
ages, the plan includes the conservation of risk areas of steep slopes, water courses and unique biodiversity areas and analyzes different scenarios and their legal feasibility. Results show that by enforcing legislation and not constructing on risk areas, a great part of the natural vegetation with good connectedness can be conserved. If special ecological areas are introduced, conservation areas and their connectedness increase. That said, existing regulations are insufficient, dispersed or not enforced.

Keywords: green infrastructure, ecosystem services, risks, metropolitan area, Tijuana.

\section{Introducción}

Los paisajes son un nivel de organización de los ecosistemas y la expresión perceptible del sistema de procesos ecológicos en un contexto físico-espacial determinado (Forman, 1995). Constan de tres elementos estructurales: fragmentos, corredores de hábitat y una matriz que es el hábitat más extenso y conectado de un paisaje. La distribución espacial o patrón de estos elementos crea mosaicos de unidades morfológicas y funcionales, en los que la función está determinada por flujos de energía, materiales (vegetación, animales, energía, minerales, agua y otros elementos) a través del paisaje. La conectividad o grado de conexión espacial entre los elementos del paisaje, tiene efectos ecológicos sobre estos flujos (Forman, 1995). Asimismo, existen procesos de disturbios, incertidumbre y riesgo que provocan que los ecosistemas cambien continuamente sobre ciertos rangos que varían en tiempo, magnitud y escala. Se considera disturbio al evento que altera significativamente el patrón de variación de la estructura y función de un sistema (Wolch, 1996).

Los seres humanos han modificado la superficie terrestre con agricultura, ganadería y zonas urbanas. Alrededor de 33\% se ha convertido en agrícola y de pastoreo (Defries, Foley y Asner, 2004). Aunque las zonas urbanas solo representan 1-3\% de los cambios, en ellas se concentra más de $50 \%$ de la población mundial y por lo tanto del consumo de recursos y de contaminación, con grandes implicaciones a escala local, regional y potencialmente mundial (Schneider, Friedl y Potere, 2009).

Los asentamientos urbanos modifican el paisaje estableciendo un sistema artificial y dinámico, que modifica los ciclos geoclimáticos, hidrológicos y ecológicos, afectando a los ecosistemas que les rodean y a sí mismas (Puente, 1996). Estos ciclos no solo transportan y distribuyen materia y energía, sino que son mecanismos de autorregulación que estabilizan las condiciones del espacio para todas las formas de vida, incluyendo la del ser humano (Flores, Picket, Wayne, Pouyat y Pirani, 1998). Con la modificación del paisaje, la escala de los disturbios naturales cambia de magnitud, frecuencia e intensidad y se introducen nuevos disturbios, barreras biogeográficas y grados de conectividad (Alberti y Marzluff, 2004).

Las ciudades son las principales emisoras de gases de efecto invernadero, clave del cambio climático (Wilby y Perry, 2006). Producen aumento de temperatura (isla de calor urbana) (Wilby y Perry, 2006) y escorrentías debido a las superficies impermeables (Whitford, Ennos y Handley, 2001), afectan la calidad del aire y del agua (McKinney, 2002) y producen pérdida de hábitat y de biodiversidad (Wu, 2008).

Estas acciones han desequilibrado a los ecosistemas, disminuyendo la cantidad y calidad de servicios que proporcionan (Defries et al., 2004). Los servicios ecosistémicos son los beneficios que obtiene la sociedad de la naturaleza. Pueden ser de provisión tangibles, como los alimentos y la madera; de regulación, como la modulación del 
clima y la erosión; culturales materiales o inmateriales, que dependen de percepciones humanas; y de sustento, aquellos procesos ecológicos indispensables para que funcionen los ecosistemas, como la limpieza del aire, entre otros (Balvanera y Cotler, 2011).

Por lo tanto, las zonas urbanas dependen espacialmente de su grado de adecuación a las condiciones naturales sobre las que reposan y a la dinámica de los fenómenos naturales a los que están sujetas, por lo que son altamente dependientes y vulnerables a la estabilidad de los ciclos de la naturaleza (Puente, 1996).

La resiliencia es la capacidad de los ecosistemas interconectados de persistir en el paisaje ante disturbios y seguir con su estructura y funciones (Holling y Gunderson, 2002). Espacialmente se relaciona con las conexiones de un fragmento con su entorno y de factores internos (Nyström y Folke, 2001). En las ciudades, la capacidad de resiliencia depende de la forma urbana, de los patrones de uso del suelo y de los procesos ecológicos locales y espaciales (Colding, 2007; Pickett, Cadenasso y Grove, 2004). Cuando se pierde la resiliencia, el ecosistema se vuelve más vulnerable a disturbios que antes podría haber absorbido (Holling y Gunderson, 2002).

Si se concibe a las zonas urbanas como sistemas dinámicos, de auto-organización, se puede construir capacidad de resiliencia, aunque no se pueda predecir la magnitud, frecuencia o extensión de los disturbios, pueden ofrecer servicios ecosistémicos a largo plazo, en un contexto de dinámica y disturbios urbanos (Ahern, 2013). Existe entonces la necesidad de establecer estrategias de planificación que puedan abordar la gestión de resiliencia en el marco urbano-territorial (Moreno, 2013).

Se sabe que las áreas verdes en las ciudades proporcionan múltiples beneficios: ayudan a reducir el efecto de isla de calor urbano y mejoran la hidrología al evitar la escorrentía superficial, mientras recargan las aguas subterráneas. También pueden actuar como amortiguadores ante eventos extremos como inundaciones, y como sumideros del agua pluvial, reduciendo los riesgos de desastres y proporcionando adaptación (Benedict y McMahon, 2006; Tzoulas et al., 2007).

Los principios de la ecología del paisaje, bajo el modelo de fragmento-corredor-matriz, proporciona una taxonomía de áreas verdes (Forman, 2008) que ayuda a crear arreglos espaciales del paisaje más sostenibles (Ndubisi, 2002). Estos principios son considerados en el concepto de infraestructura verde (IV), concebida como una red interconectada de áreas verdes — urbanas, periurbanas y rurales- que conserva y aporta múltiples funciones a los ecosistemas y servicios ambientales para la población humana (Benedict y McMahon, 2006). El concepto lleva implícita la conectividad, que contribuye al funcionamiento del paisaje (Momm-Schult et al., 2013), a proveer servicios ambientales y a construir capacidad de resiliencia (Moreno, 2013).

Con esta visión, el presente artículo expone los alcances de la planificación y el diseño del paisaje de IV enfocada a la mitigación de riesgos por inundaciones, derrumbes y deslaves y la conservación de la biodiversidad, en el contexto de la zona metropolitana de Tijuana-Tecate-Rosarito (zMTTR) en Baja California, México. El objetivo es encontrar zonas adecuadas en áreas aún no desarrolladas para establecer iv, medir su grado de conectividad y determinar su grado de factibilidad en el marco legislativo actual.

\section{Área de estudio}

Reconocida en el 2004 como unidad geográfica, económica y social, para planear y regular conjuntamente el desarrollo (Gobierno del Estado de Baja California, 2004, p. 16), la 
zMTTR se localiza al noroeste de Baja California, en México. Colinda al norte con Estados Unidos (EE. UU.) y al oeste con el océano Pacífico, y comprende 139864.44 ha (1.68\% del estado) (Venegas y Rojas, 2009). Se compone de tres municipios: Tijuana, Tecate y Playas de Rosarito (Rosarito) (Figura 1).

Figura 1: Localización del área de estudio

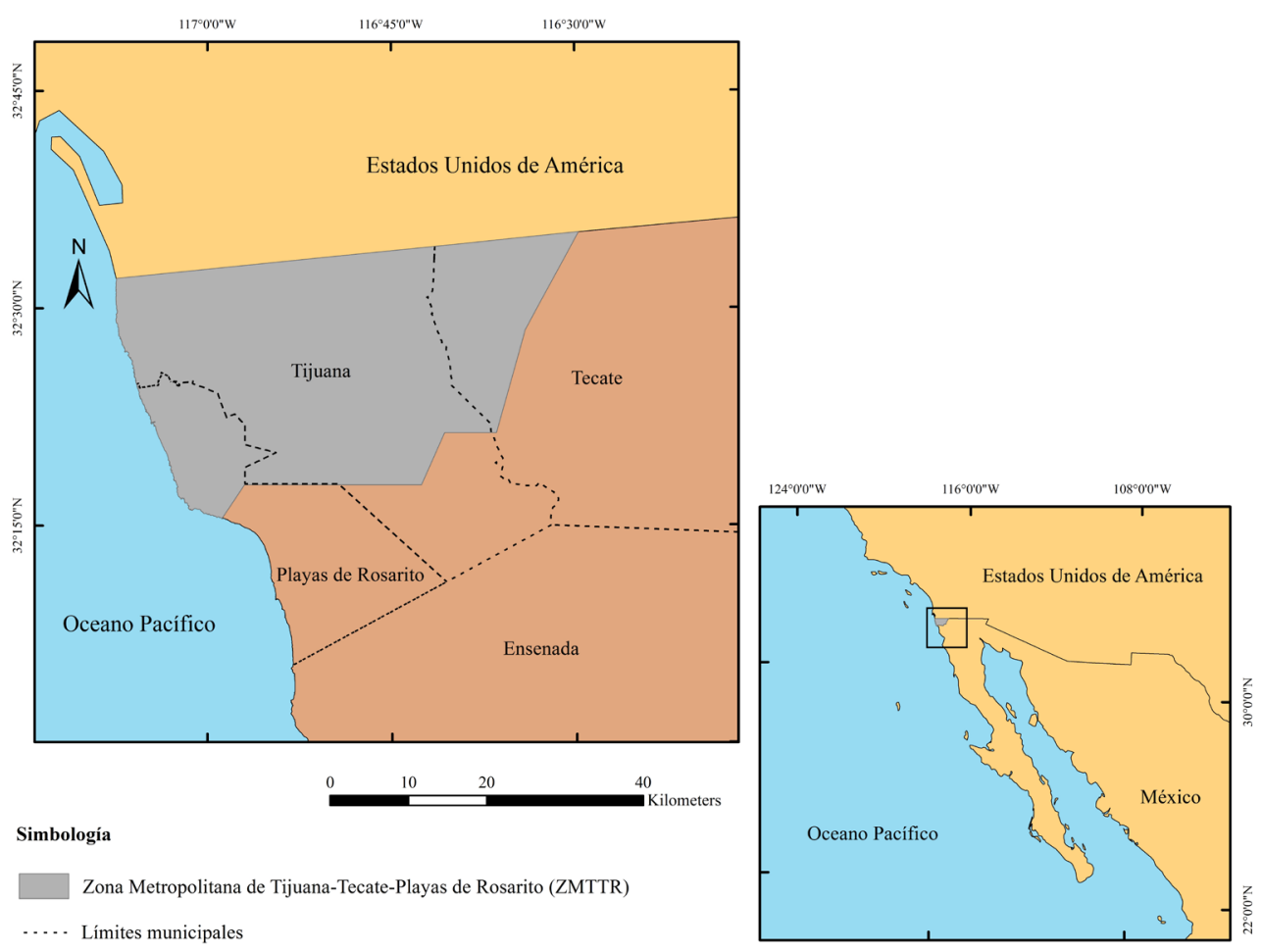

Fuente: Elaboración propia.

El clima que impera es tipo mediterráneo, con inviernos fríos ylluvias en invierno, templado con verano cálido, y temperaturas de entre $10^{\circ}$ y $22^{\circ} \mathrm{C}$ (García, 2004). La precipitación anual varía con la elevación, entre 273 y $500 \mathrm{~mm}$ anualmente. En los municipios de Tijuana y Tecate, el río Tijuana se forma de la confluencia de una intermitente y densa red hidrológica compartida con EE. UU., que en invierno puede ser torrencial, pero que desaparece el resto del año. El río atraviesa la ciudad de Tijuana y descarga sus aguas a través de un estero al océano Pacífico que es área protegida de EE. UU. En el municipio de Rosarito, los arroyos existentes drenan al Pacífico (Instituto Nacional de Estadística Geografía e Informática [Inegi], 1995). Con escasa precipitación y escasos cuerpos de agua superficial el área sufre de carencia de agua (Gobierno del Estado de Baja California, 2013).

Gran parte del área presenta una topografía accidentada (Ojeda-Revah, 1999), con suelos que se erosionan fácilmente, alta permeabilidad pero baja retención del agua, por lo que se saturan rápido, son inestables y fáciles de inundarse. Al remover la vegetación, se presentan problemas de infiltración de agua, lo que favorece la escorrentía superficial y la erosión (Food and Agriculture Organization of the United Nations [FAO], 2001; Inegi, 2004; Secretaría de Medio Ambiente y Recursos Naturales [Semarnat], 2012). 
Asimismo, la zona es susceptible a sismos, por estar en la región de convergencia de las placas Norteamericana y Pacífico (Mendoza, Acosta y Vázquez, 2009), lo que agrava los problemas de deslizamientos.

La zona se encuentra dentro de la Provincia Florística de California, rica en endemismos y diversidad de especies (Riemann y Ezcurra, 2007), considerada como uno de los 25 hotspots de biodiversidad del mundo amenazados por el rápido crecimiento urbano (Myers, Mittermeier, Mittermeier, Fonseca y Kent, 2000). Los principales tipos de vegetación que se desarrollan en el área son: bosque de encinos, vegetación riparia, matorral costero y chaparral (Oberbauer, 1999). Cabe mencionar que el chaparral y el matorral costero son ecosistemas adaptados a un régimen de incendios naturales y algunas de sus especies requieren de ellos para su permanencia (Lippitt, Stow, O’Leary y Franklin, 2013).

Debido al crecimiento urbano disperso, estos ecosistemas se han reducido y fragmentado para dar paso a lo urbano y a pastizales inducidos (Farley, Ojeda-Revah, Atkinson y EatonGonzález, 2012), amenazando la biodiversidad regional (Riemann y Ezcurra, 2007).

Aunque las tasas de crecimiento de Tijuana, Tecate y Rosarito disminuyeron en el periodo 2000-2010 (2.56. 2.65 y 3.63 respectivamente) con relación al periodo 1990-2000 (4.94, 4.19 y sin información ${ }^{1}$ ), estas aún son mayores a las del promedio del país (1.4\%) (Inegi, 2013). Para el 2010 la población de la zMTTR, alcanzó 1751430 habitantes (55\% del estado), distribuida en 8.9, 5.8 y 5.2\% respectivamente (Inegi, 2010).

Debido a su ubicación en la frontera con EE. UU., Tijuana particularmente creció rápido promovida por un alto flujo de migración, como un centro de comercio y servicios y un sitio de industrialización para abastecer mercados extranjeros (Sánchez-Rodríguez, 2011). Su población creció de 240000 en 1970 a 1519454 en 2010 (Inegi, 2010) y su superficie aumentó en promedio 1.75 ha diario entre 1972 y el 2000, cifra que alcanzó 5.24 ha entre 1984 y 1994 (Bringas y Sánchez, 2006).

Con un crecimiento acelerado, escasa planeación y un desfase de las capacidades para atender las demandas de la población (Sánchez-Rodríguez, 2011), gran parte de la ciudad tuvo un origen irregular (casi 57\%) (Alegría y Ordoñez, 2005). Con ello, el número y superficie de asentamientos humanos aumentaron progresivamente sobre lugares de mayor riesgo (pendientes pronunciadas y cauces de agua) (Bringas y Sánchez, 2006). Las modificaciones en el paisaje sobre grandes áreas con urbanización incompleta, redes de drenaje pluvial ineficientes y cambios en la estabilidad de laderas por urbanización, provocaron la reducción de la infiltración del agua de lluvia y la aceleración del descenso de los escurrimientos, a la vez que aumentaron los riesgos de inundaciones periódicas y se crearon problemas de estabilidad de taludes durante las épocas de lluvias (SánchezRodríguez, 2011). De hecho, en 1993 Tijuana sufrió las consecuencias de una precipitación mayor de la usual, provocando deslaves, inundaciones y daños materiales y económicos, situación que no ocurrió en localidades rurales cercanas, ni en laderas provistas de vegetación (Bocco, Sánchezy Riemann, 1993), que a la vez permitían la infiltración de agua en el subsuelo y disminuían la escorrentía superficial (American Planning Association [APA], 2013).

Por su parte, Tecate presenta inundaciones, derrumbes y deslaves (Ganster, 2002), estos últimos pueden ser intensificados por la actividad de la falla de San Andrés (Ayuntamiento de Tecate, 2011) y Playas de Rosarito es afectado por erosión, inundaciones e inestabilidad de taludes (Mendoza et al., 2009).

En este escenario los parques urbanos han pasado a segundo término. En Tijuana cubren menos de $1 \%$ de la superficie o $1 \mathrm{~m}^{2}$ de parques por habitante, pero solo $35 \%$ de la

\footnotetext{
${ }^{1}$ Rosarito se convirtió en municipio en 1995, antes pertenecía a Tijuana.
} 
población tienen acceso a ellos (400 m), además de que la mayoría son muy pequeños, están en mal estado y desprovistos de vegetación (Huizar y Ojeda-Revah, 2014). Tecate solo cuenta con tres parques públicos y dos de paga (Sierra, 2002) y según el Ayuntamiento de Playas de Rosarito (2014, p.140), este cuenta con " $16.5 \mathrm{~m}^{2}$ de áreas verdes por habitante en 40 fraccionamientos, aunque la cifra es de $5.5 \mathrm{~m}^{2} \mathrm{en}$ el área de playa”.

\section{Métodos y técnicas}

Con el objetivo de conocer el estado actual de la ZMTTR, se construyó un mapa de usos del suelo y tipos de vegetación usando ArcGis 10.2 e imágenes de satélite spot (31 de diciembre de 2012 y 21 de enero de 2013), escala 1:50 000 y con 30 m de resolución. La zona de estudio se estableció con base en Venegas y Rojas (2009). Los usos del suelo y tipos de vegetación se interpretaron visualmente y se digitalizaron en pantalla, corroborando con Google Earth, con el mapa del 2005 de la Cuenca del Río Tijuana elaborado por Farley et al. (2012) y con trabajo de campo, verificando la asignación de $20 \%$ del total de los polígonos identificados. Se usó la clasificación de usos del suelo y tipos de vegetación de Ojeda-Revah (1999) y adaptada a la región (bosque de encino, chaparral, matorral costero, vegetación riparia, agricultura de temporal y de riego, urbano y presas).

Para determinar el potencial de infraestructura verde, se construyeron tres escenarios usando los siguientes criterios:

1. Áreas de riesgo (pendientes $>35 \%$ y cursos de agua con zonas de amortiguamiento y vegetación riparia).

2. Áreas de riesgo y lugares ecológicos sobresalientes.

3. Áreas de riesgo, lugares ecológicos sobresalientes y cinturón de vegetación natural rodeando ciudades.

En el primer escenario, las zonas de riesgo que se seleccionaron con base en la legislación federal, fueron las pendientes mayores a $35 \%$ por no ser aptas para la construcción por probabilidad de derrumbe y consideradas para conservación, recarga de mantos acuíferos y para evitar contaminación (Secretaría de Desarrollo Social [Sedesol], 1993/2014). Las pendientes pronunciadas se obtuvieron a partir de los Modelos Digitales de Elevación (MDE), escala 1:50 000 del Inegi (2014).

También se consideraron los cursos de agua naturales, en los que la Ley de Aguas Nacionales por riesgo a inundaciones restringe la construcción y establece una zona de amortiguamiento de 10 metros (Secretaría de Agricultura y Recursos Hidráulicos [sAHR], 1992/2014). Para crear el mapa se determinó la dirección del flujo de drenaje, se calculó el flujo acumulado (red hídrica) estableciendo órdenes de drenaje (Strahler, 1957) y se demarcaron las zonas de amortiguamiento en aquellos de mayor afluencia. En las áreas en donde la vegetación riparia era más extensa, las zonas de amortiguamiento se ampliaron, ya que tienen gran probabilidad de inundarse (APA, 2013).

Para el escenario dos, los lugares ecológicos sobresalientes se obtuvieron con la superposición de la distribución de poblaciones vegetales especiales descritas por Oberbauer (1999) y el único fragmento de bosque de encino de la zMTTR, identificados en campo y la Región Terrestre Prioritaria Santa María-El Descanso (Región Prioritaria) designada por la Comisión Nacional para Conocimiento y Uso de la Biodiversidad por su alto endemismo florístico (Comisión Nacional para Conocimiento y Uso de la Biodiversidad [Conabio], 2012).

En el tercer escenario, y con la idea de contener el crecimiento urbano fragmentado y aumentar la conectividad de la infraestructura verde propuesta, se trazó un cinturón verde alrededor de las tres ciudades. Dado que no existen valores establecidos para determinar su 
ancho, se tomó como base los $2 \mathrm{~km}$ calculados para corredores de grandes mamíferos en el sur de California (Beier, Penrod, Luke, Spencer y Cabañero, 2006). Al concebirse como cinturón verde y no como corredor, este valor se redujo promediándolo con los 0.30480 $\mathrm{km}$, ancho establecido para corredores cortos por el San Diego Environmental Mitigation Program Working Group (2011, p. 4) que forma parte de la Agencia de Planeación Regional de San Diego (SANDAG). El valor resultante se redondeó a $1 \mathrm{~km}$ de ancho.

La estructura del paisaje y su conectividad se determinó con índices de composición y configuración (Tabla 1), usando el programa FRAGSTATS 4. Los primeros se refieren a la diversidad y abundancia de los tipos de fragmentos dentro del paisaje, sin considerar su ubicación espacial, mientras que los últimos, sí consideran su localización y cómo se distribuyen ente ellos (McGarigal, 2006).

Tabla 1: Índices del paisaje

\begin{tabular}{|c|c|c|}
\hline & Métrica & Fórmulas \\
\hline Uี & $\begin{array}{l}\boldsymbol{n}_{i j}=\text { Número de fragmentos por categoría. } \\
\boldsymbol{s}_{i j}=\text { Área por categoría. } \\
\text { Porcentaje de cobertura por categoría. } \\
\text { Superficie y porcentaje del fragmento más grande. }\end{array}$ & \\
\hline ن̃ & $\begin{array}{l}\text { Índice de cohesión C } \\
\mathrm{p}_{i j}=\text { perímetro del fragmento } i j \text { en términos del número de celdas } \\
\mathrm{a}_{i j}=\text { área del fragmento } i j \text { en términos del número de celdas } \\
\mathrm{z}=\text { total del número de celdas en el paisaje. } \\
\text { Índice de vecino más cercano (distancia euclidiana) ENN. } \\
\mathrm{h}_{i j}=\text { Distancia del fragmento } i j \text { al fragmento más cercano de la } \\
\text { misma clase, basado en la distancia más corta de borde a borde } \\
\text { de los fragmentos. } \\
\text { Índice del fragmento más grande LPI. } \\
\mathrm{a}_{i j}=\text { área del fragmento } i j \\
\mathrm{~A}=\text { área total del paisaje. }\end{array}$ & $\begin{array}{c}C=\left[1-\frac{\sum_{i=1}^{m} \sum_{j=1}^{n} p * i j}{\sum_{i=1}^{m} \sum_{j=1}^{n} p * i j \sqrt{a * i j}}\right] \cdot\left[1-\frac{1}{\sqrt{2}} \cdot(100)\right] \\
\mathrm{ENN}=h_{i j} \\
L P I=\frac{\max ^{n}\left(a_{i j}\right)}{A}(100)\end{array}$ \\
\hline
\end{tabular}

Fuente: McGarigal, Cushman y Ene (2012) y Pauchard, Aguayo y Alaback (2006).

Se analizó el grado de conectividad de la vegetación natural reclasificada en una sola categoría en su estado actual y en los escenarios construidos, usando los índices de fragmento más grande, de cohesión y del vecino más cercano. El primero es el porcentaje del paisaje compuesto por el fragmento más grande al nivel de clase, los otros dos analizan la distribución de los fragmentos en el paisaje y la distancia que hay entre ellos (McGarigal et al., 2012). El segundo mide la conectividad física, calculando qué tan cerca están los fragmentos. A mayor cohesión, mayor conectividad entre ellos. Mientras más alto sea el valor, mayor es el número de fragmentos agregados, lo que permite el flujo de materia e información a través del paisaje y aumenta la conectividad (Pauchard et al., 2006). El tercero mide la distancia del centro del 
polígono al borde de su vecino más cercano del mismo tipo. A medida que el valor se acerca a cero, la distancia del vecino más cercano decrece, es decir, que los fragmentos se encuentran más cerca unos de otros (McGarigal et al., 2012), de este índice se sacó la media.

Finalmente, para poder establecer de factibilidad de las propuestas de IV, se realizó un análisis del marco legislativo en materia de riesgos, de conservación de ecosistemas naturales y de áreas verdes urbanas.

\section{Resultados}

La ZMTTR aún conserva casi la mitad de su superficie con vegetación natural en diferentes grados de conservación a pesar de estar cubierta en una tercera parte por áreas urbanas. Los ecosistemas de mayor extensión son el matorral costero, seguido del chaparral y de la vegetación de riparia y de un pequeño fragmento de bosque de encino al suroeste. Sin embargo, los ecosistemas naturales (principalmente el matorral costero y el chaparral) están fragmentados por las tres ciudades y por la presencia de muchos pequeños fragmentos de pastizal inducido alrededor de las zonas urbanas. Las ciudades de Tijuana y Rosarito están integradas en un solo fragmento, unido a Tecate y al Valle de las Palmas por muchos fragmentos urbanos pequeños conectados por carreteras (Tabla 2, Figura 2).

Tabla 2: Superficies, porcentajes y número de fragmentos de usos del suelo y tipos de vegetación de la zona metropolitana Tijuana-Tecate-Rosarito en 2012

\begin{tabular}{llrrr}
\hline & \multicolumn{1}{c}{ Cobertura } & Superficies (ha) & $\begin{array}{c}\text { \% de la } \\
\text { zMTTR }\end{array}$ & $\begin{array}{c}\text { Número de } \\
\text { fragmentos }\end{array}$ \\
\hline \multirow{2}{*}{ Natural } & Bosque de encino & 84.44 & 0.06 & 1 \\
& Chaparral & 22895.18 & 16.37 & 36 \\
& Matorral costero & 40400.47 & 28.89 & 72 \\
& Vegetación riparia & 6118.45 & 4.37 & 109 \\
& Subtotal & 69498.64 & 49.69 & 218 \\
\multirow{3}{*}{ Uso humano } & 1853.88 & 1.33 & 28 \\
& Agricultura de riego & 1738.29 & 1.24 & 47 \\
& Agricultura de temporal & 21902.16 & 15.66 & 152 \\
& Pastizal inducido & 410.06 & 0.29 & 4 \\
& Presa & 44461.42 & 31.79 & 62 \\
& Urbano & 70365.81 & 50.31 & 293 \\
& Subtotal & 139864.44 & 100 & 511 \\
\hline
\end{tabular}

Fuente: Elaboración propia. 
Figura 2: Usos del suelo y tipos de vegetación en la zona metropolitana Tijuana-Tecate-Rosarito en 2012

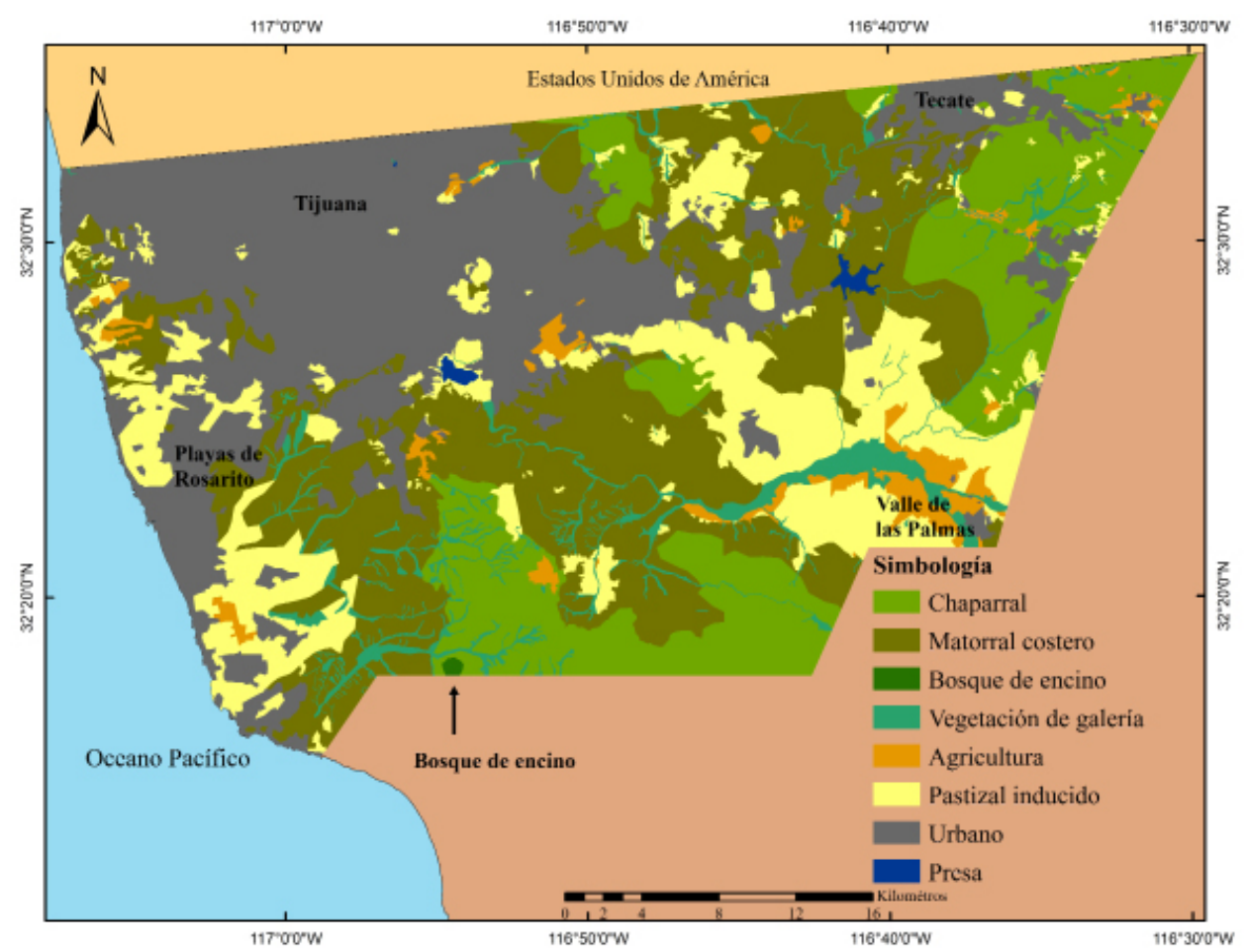

Fuente: Elaboración propia con base en interpretación de imagen SPOT (Estación de Recepción México [ERMEX], 2012, 2013).

La vegetación natural se compone de 73 fragmentos, de los cuales el mayor concentra a 96\% de su extensión total, desde el sureste de Rosarito hacia el este de Tecate conectado por ecosistemas riparios. Otro fragmento relativamente grande se encuentra aislado entre Tijuana y Tecate (862 ha), el resto son menores de 500ha, e inclusive 63 son menores a 50 ha. Los índices de conectividad (cohesión 99.6 y vecino más cercano 361.9), reflejan que la mayor parte de la vegetación natural está agregada, pero que existen muchos fragmentos muy pequeños aislados y a considerable distancia unos de otros (Tabla 3, ver Figura 2).

\section{Escenarios}

En el primer escenario las zonas de riesgo cubren casi $17.6 \%$ del área total, distribuidas en 335 fragmentos principalmente entre Tijuana y Tecate y al sureste. Con ellas se conservaría $35.4 \%$ de la vegetación natural (una tercera parte del matorral costero y del chaparral y toda la vegetación riparia), dentro de la cual se encuentran las zonas con biodiversidad especiales descritas por Oberbauer (1999) (Figura 3a) y solo una pequeña fracción del único fragmento de bosque de encino. El fragmento más grande conformado por el afluente principal del Río Tijuana y su vegetación aledaña incluyendo al Valle de las Palmas, supera las 10000 ha. Otros fragmentos grandes están entre Tijuana y Tecate (aproximadamente $4000 \mathrm{ha}$ ) y al sur de Rosarito (mayor a $1000 \mathrm{ha}$ ). El resto de los fragmentos son menores de 1000 ha e inclusive 91\%, son menores de 50 ha (Tabla 3). 
Tabla 3: Superficie conservada, porcentaje de tipos de vegetación, medidas de composición y de conectividad por escenario

\begin{tabular}{llrrr}
\hline & & \multicolumn{3}{c}{ Escenarios } \\
& & $\mathbf{1}$ & $\mathbf{2}$ & \multicolumn{1}{c}{$\mathbf{3}$} \\
\hline Superficie conservada (ha) & & 24582.57 & 30101.09 & 35460.56 \\
\hline Vegetación natural conservada (ha) & Bosque de encino & 24582.57 & 29450.11 & 34169.63 \\
\hline \multirow{2}{*}{$\begin{array}{l}\text { Conservación de tipos de } \\
\text { vegetación (\%) }\end{array}$} & Chaparral & 4.12 & 100.00 & 100.00 \\
& Matorral costero & 30.26 & 42.63 & 49.58 \\
& Vegetación riparia & 28.38 & 33.10 & 39.50 \\
\hline \multirow{2}{*}{ Otros usos } & Agricultura & 100.00 & 100.00 & 100.00 \\
\hline \multirow{3}{*}{ Medidas de composición } & Pastizal inducido & 67.88 & 67.88 & 140.51 \\
& \% con respecto a vegetación natural & 0 & 583.10 & $1,150.42$ \\
\hline & Supero de fragmentos de vegetación natural & 35.37 & $42.38^{*}$ & $49.17^{*}$ \\
Índices de configuración & 335 & 303 & 269 \\
(conectividad) & Fragmento más grande & 10133.99 & 19515.82 & 30935.78 \\
\hline & Cohesión (\%) & 6.98 & 13.38 & 22.04 \\
& Vecino más cercano & 97.77 & 98.65 & 99.38 \\
& & 279.24 & 284.92 & 290.64 \\
\hline
\end{tabular}

*Estos porcentajes no incluyen agricultura y pastizal inducido.

Escenario 1. Áreas de riesgo (pendientes $>35 \%$ y cursos de agua con zonas de amortiguamiento y vegetación riparia).

Escenario 2. Áreas de riesgo y lugares ecológicos sobresalientes.

Escenario 3. Áreas de riesgo, lugares ecológicos sobresalientes y corredores con vegetación natural.

Fuente: Elaboración propia.

Figura 3a: Escenarios de conservación para la zona metropolitana Tijuana-Tecate-Rosarito. Escenario 1 áreas de riesgo (pendientes $>35 \%$ y cursos de agua)

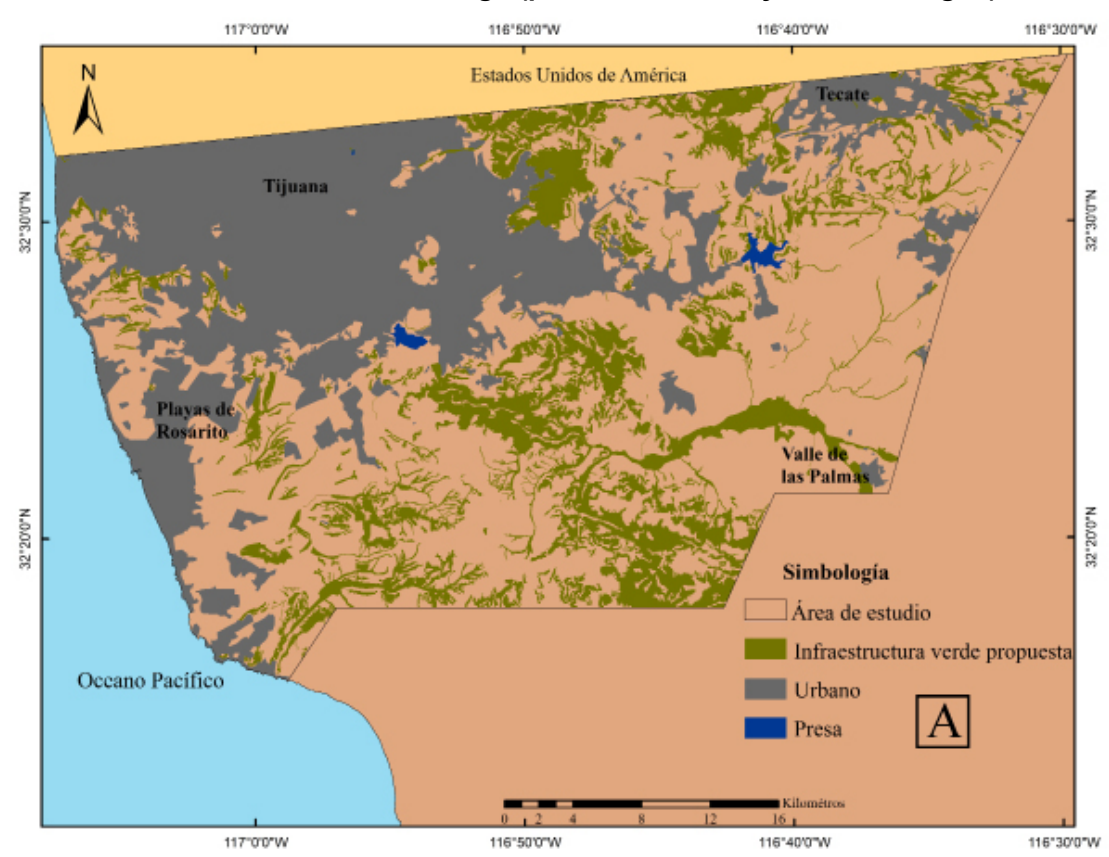

Fuente: Elaboración propia. 
$\mathrm{Al}$ añadir los lugares ecológicos sobresalientes (segundo escenario), el área a conservar aumentaría a $21.5 \%$ de la ZMTTR y $42.4 \%$ de la vegetación natural (poco más de un tercio del matorral costero y chaparral y todo el bosque de encino y la vegetación riparia) y el número de fragmentos se reduce casi $10 \%$. Su distribución se extiende en el límite sur, con el gran fragmento de la Región Prioritaria (Conabio, 2012) (Figura 3b) que al fusionarse con un fragmento del Valle de las Palmas duplica su superficie. El resto de los fragmentos son menores de 1000 ha, pero cerca de $93 \%$ de estos, son menores de 50 ha. Cabe mencionar que este escenario incluye agricultura y pastizales inducidos, que conforman 2.2\% del área a conservar (consideradas en el análisis de conectividad porque pueden ser restauradas y 105.8 ha de una zona urbana (no incluida en el análisis de conectividad) originalmente contenidos en el área prioritaria (ver Tabla 3).

Figura 3b: Escenario 2, áreas de riesgo (pendientes $>35 \%$ y cursos de agua) y lugares ecológicos sobresalientes

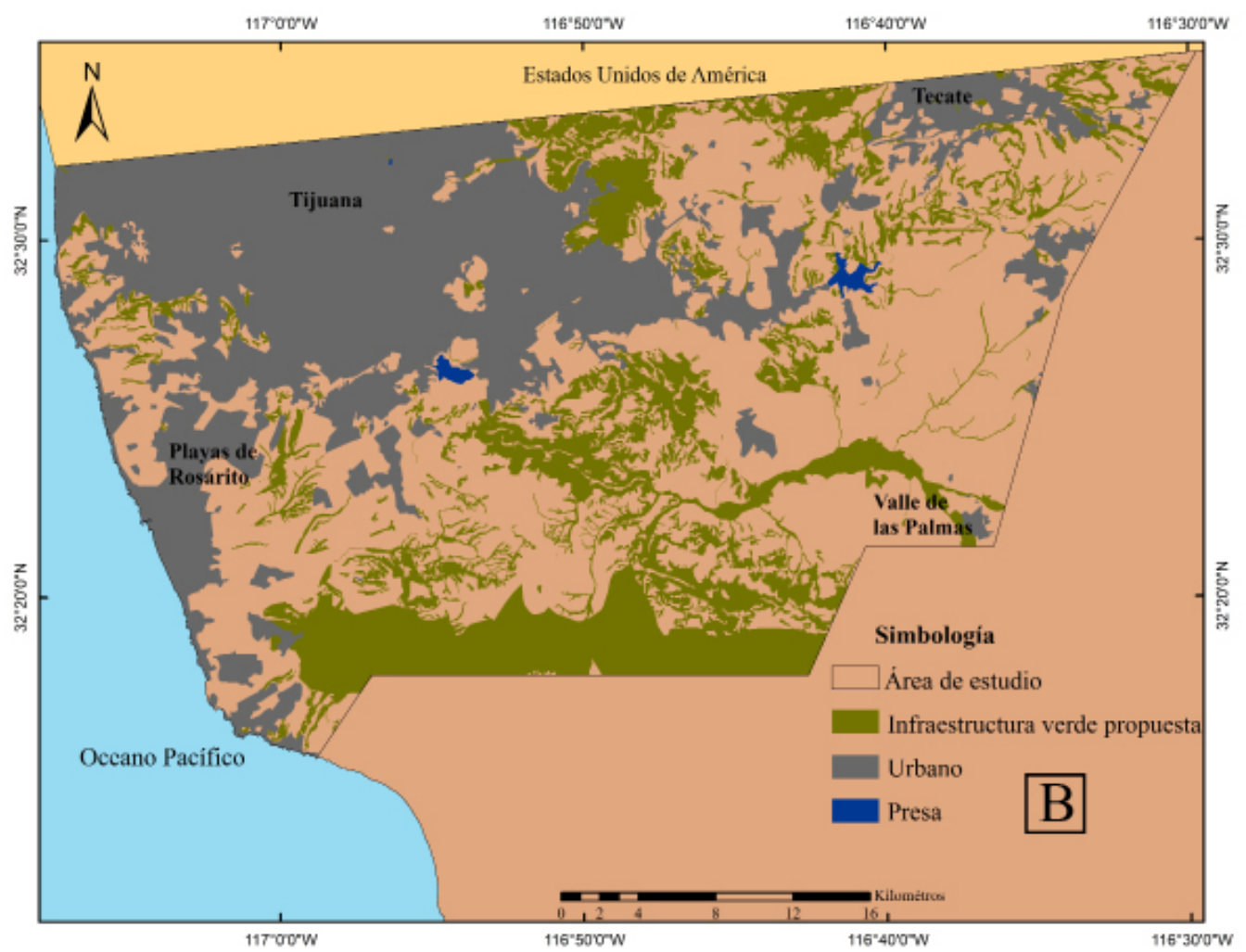

Fuente: Elaboración propia.

En el tercer escenario, al trazar un cinturón verde alrededor de las áreas urbanas, la superficie a conservar alcanzaría una cuarta parte de la zona de estudio, lo que representa 49.2\% de la vegetación original (casi la mitad del chaparral, $40 \%$ del matorral costero y todo el bosque de encino y la vegetación riparia), dispersa en 255 fragmentos. Al ampliar la conectividad, el fragmento más grande aumenta poco más de 10000 ha. El resto de los fragmentos son menores de 500 ha e inclusive casi $95 \%$ de estos, son menores de 50 ha (Figura 3c). La superficie de agricultura y pastizales inducidos aumenta a 3.8\% del área a conservar incluidas en el análisis de conectividad porque pueden ser conservadas (como se observa en la Tabla 3). 
Figura 3c: Escenario 3, áreas de riesgo (pendientes $>35 \%$ y cursos de agua), lugares ecológicos sobresalientes y corredores de vegetación natural

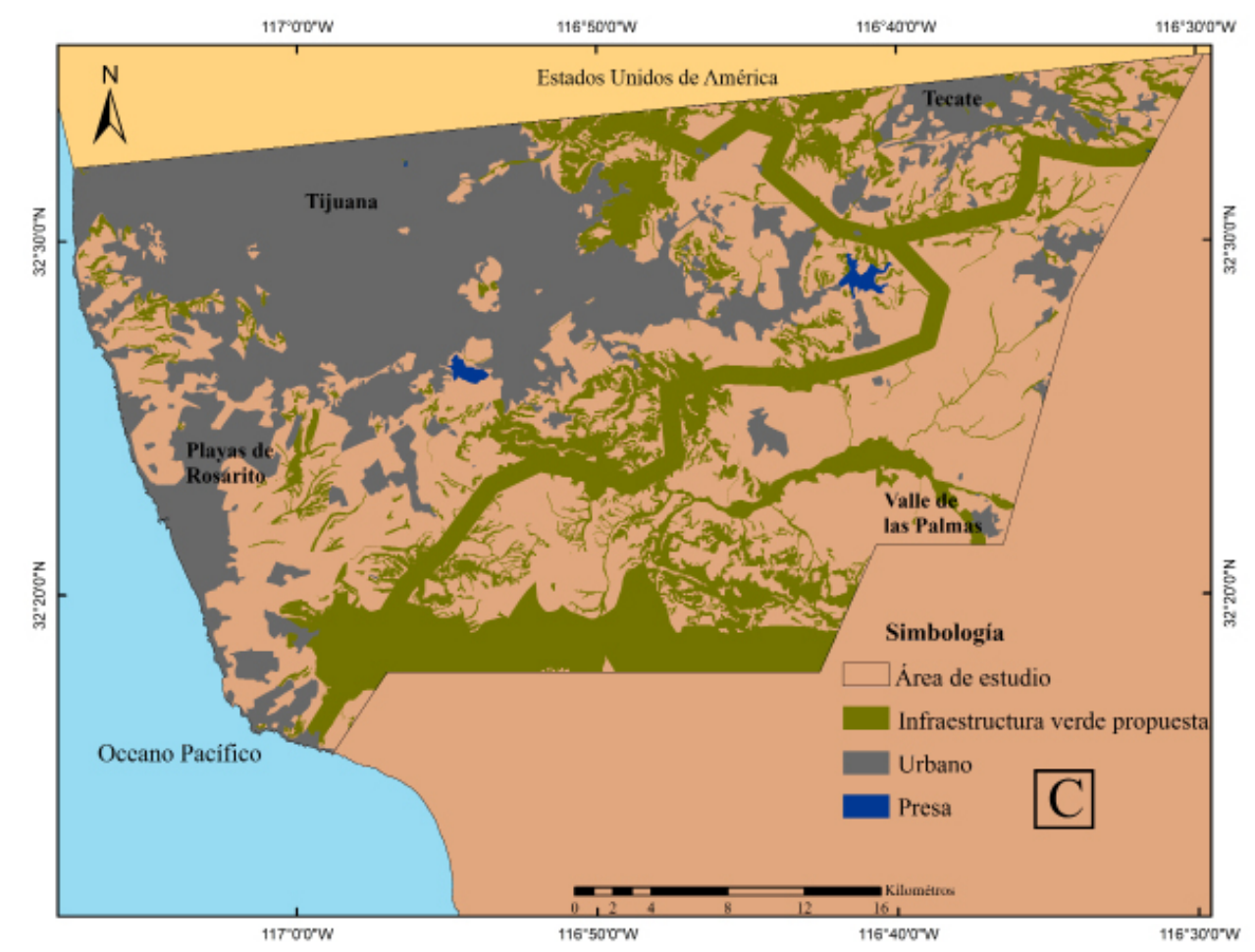

Fuente: Elaboración propia.

En lo que se refiere a la conectividad de los escenarios de conservación propuestos (ver definición de índices en apartado de métodos y técnicas), el índice del fragmento más grande que en su estado original cubría $96.4 \%$ de la vegetación natural, se reduce hasta $7.5 \%$ en el primer escenario, pero casi se duplica en el segundo escenario y se triplica en el tercero alcanzando a conservar casi la mitad de la vegetación natural existente. Con ello, el número de fragmentos, aunque alto desde el primer escenario, disminuye gradualmente. Sin embargo, en todos los escenarios existen muchos fragmentos menores a 50 ha. El índice del vecino más cercano aumenta paulatinamente, mostrando reducción de la dispersión, mientras que la cohesión aumenta conforme se unen fragmentos, incrementando la conectividad (Véase Tabla 3).

\section{Legislación}

Los resultados del análisis del marco legislativo en el que se inserta esta propuesta se resumen en la Tabla 4. En materia de riesgos la Ley de Aguas Nacionales (sarh, 1992/2014) prohíbe la construcción sobre cauces naturales y especifica áreas de amortiguamiento. Asimismo, aunque las leyes de asentamientos humanos federal y del estado de Baja California (Gobierno del Estado de Baja California, 1994/2013; Sedesol, 1993) mencionan que no se debe construir sobre zonas de riesgo con pendientes pronunciadas, estas no se especifican. Al nivel regional y municipal, casi todos los reglamentos y planes y programas de desarrollo urbano prohíben la construcción en lugares con riesgos, en áreas con 
pendientes pronunciadas $(>35 \%$, en Rosarito $>30 \%$ ) y en cauces naturales, pero no detallan medidas. En lo que se refiere a la creación de áreas naturales protegidas (ANP), el estado y los municipios tienen facultad de crearlas, (Secretaría de Medio Ambiente y Recursos Naturales y Pesca [Semarnap], 1988). No obstante, en la zona de estudio, a la fecha no se ha declarado ninguna.

Tabla 4: Marco legal de la zona metropolitana Tijuana-Tecate-Rosarito en materia de riesgos (pendientes y cursos de agua), áreas naturales protegidas y parques urbanos

\begin{tabular}{|c|c|c|c|c|c|c|}
\hline & \multirow[t]{2}{*}{$\begin{array}{l}\text { Leyes, planes y reglamentos referentes } \\
\text { a la ZMTTR }\end{array}$} & \multicolumn{2}{|c|}{$\begin{array}{l}\text { Zonas de } \\
\text { riesgo }\end{array}$} & \multicolumn{2}{|c|}{$\begin{array}{c}\text { Áreas } \\
\text { verdes }\end{array}$} & \multirow[t]{2}{*}{ Observaciones } \\
\hline & & 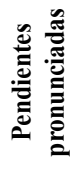 & 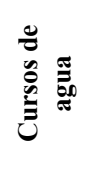 & $\hat{z}$ & 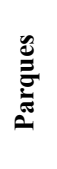 & \\
\hline \multirow{3}{*}{ 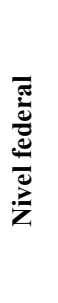 } & $\begin{array}{l}\text { Ley General del Equilibrio Ecológico y la } \\
\text { Protección al Ambiente }\end{array}$ & & & $\mathrm{X}$ & & $\begin{array}{l}\text { ANP pueden ser establecidas por esta- } \\
\text { dos y municipios. }\end{array}$ \\
\hline & Ley de Aguas Nacionales & & $\mathrm{X}$ & & & $\begin{array}{l}\text { Distancia de } 10 \mathrm{~m} \text { de canales de ríos y } \\
\text { arroyos canalizados o del límite de la } \\
\text { zona federal en estado natural. }\end{array}$ \\
\hline & Ley General de Asentamientos Humanos & $\mathrm{X}$ & $X$ & & & $\begin{array}{l}\text { No define áreas de riesgo. El estado } \\
\text { debe definir la proporción de áreas } \\
\text { verdes urbanas. }\end{array}$ \\
\hline \multirow{4}{*}{ 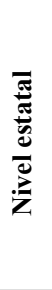 } & $\begin{array}{l}\text { Sistema Normativo de Equipamiento } \\
\text { Urbano }\end{array}$ & & & & & $\begin{array}{l}\text { Propone cuatro tipos de parques, su su- } \\
\text { perficie y equipamiento por densidad } \\
\text { de población. }\end{array}$ \\
\hline & Ley de Protección al Ambiente & & $X$ & $\mathrm{X}$ & & Establece tres tipos de ANP. \\
\hline & Ley de Desarrollo Urbano & & & & & No define áreas de riesgo. \\
\hline & Reglamento de Fraccionamientos & & & & & $\begin{array}{l}\text { Destina 3\% de área verde en fraccio- } \\
\text { namientos. }\end{array}$ \\
\hline \multirow{3}{*}{ 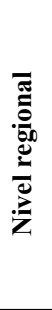 } & Plan Estratégico Metropolitano & & & & $\mathrm{X}$ & $\begin{array}{l}\text { Propone crear un sistema de parques y } \\
\text { áreas verdes. }\end{array}$ \\
\hline & $\begin{array}{l}\text { Programa Regional de Desarrollo Urbano, } \\
\text { Turístico y Ecológico del Corredor Costero } \\
\text { Tijuana-Rosarito-Ensenada. }\end{array}$ & $\mathrm{X}$ & $\mathrm{X}$ & & $\mathrm{X}$ & $\begin{array}{l}\text { Propone crear un bioparque y pro- } \\
\text { gramas de restauración y manten- } \\
\text { imiento. }\end{array}$ \\
\hline & $\begin{array}{l}\text { Programa de Ordenamiento. Zona Metro- } \\
\text { politana Tijuana-Tecate Playas de Rosari- } \\
\text { to-Ensenada }\end{array}$ & & & & $\mathrm{X}$ & $\begin{array}{l}\text { Propone recuperar arroyos, crear } \\
\text { parque Alamar y corredores verdes } \\
\text { metropolitanos. }\end{array}$ \\
\hline \multirow{5}{*}{ 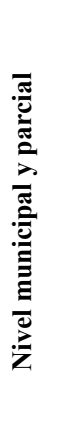 } & $\begin{array}{l}\text { Reglamento de Zonificación y Usos del } \\
\text { Suelo del Centro de Población de Tijuana }\end{array}$ & $\mathrm{X}$ & $\mathrm{X}$ & & $\mathrm{X}$ & Define a los parques urbanos. \\
\hline & $\begin{array}{l}\text { Programa de Desarrollo Urbano del Centro } \\
\text { de Población de Tijuana, BC 2010-2030 }\end{array}$ & $\mathrm{X}$ & $\mathrm{X}$ & & $\mathrm{X}$ & Prohíbe construir en pendientes $>35 \%$. \\
\hline & $\begin{array}{l}\text { Programa de Desarrollo Urbano del Cen- } \\
\text { tro de Población de Primo Tapia de Playas } \\
\text { de Rosarito 2007-2030 }\end{array}$ & $\mathrm{X}$ & $\mathrm{X}$ & & $\mathrm{X}$ & $\begin{array}{l}\text { Prohíbe construir en pendientes }>30 \% \text {. } \\
\text { Propone crear parques. }\end{array}$ \\
\hline & $\begin{array}{l}\text { Programa de Desarrollo Urbano del Centro } \\
\text { de Población de Tecate 2001-2013 }\end{array}$ & & & & $\mathrm{X}$ & $\begin{array}{l}\text { Propone restaurar el río Tecate y crear } \\
\text { nuevos parques. }\end{array}$ \\
\hline & $\begin{array}{l}\text { Programa Parcial de Desarrollo Urbano } \\
\text { Valle de Las Palmas }\end{array}$ & $\mathrm{X}$ & $\mathrm{X}$ & & $\mathrm{X}$ & $\begin{array}{l}\text { Propone crear parques. Condiciona el } \\
\text { desarrollo en pendientes de } 25-35 \% \text {. }\end{array}$ \\
\hline
\end{tabular}

Fuente: Elaboración propia con base en Ayuntamiento de Playas de Rosarito (2010); Ayuntamiento de Tecate (2003); Ayuntamiento de Tijuana (2008, 2010a, 2010b); Gobierno del Estado de Baja California (1971, 1994/2013, 2001a, 2001b, 2012); Implan (2012); Sedesol (1993/2014, 1999); Semarnap (1988). 
El tema de las áreas verdes urbanas presenta un gran rezago en materia legal. A nivel federal, la Sedesol $(1999)^{2}$ solo hace recomendaciones de superficies en función de la población; a nivel estatal, la Ley de Fraccionamientos (Gobierno del Estado de Baja California, 1971) obliga a crear un porcentaje de áreas verdes, pero no considera la densidad de población; y a nivel municipal, no existe nada que obligue a crearlas. Inclusive algunas áreas destinadas a parques, han sido utilizadas por el municipio para otro fin (construcción de vivienda, equipamiento urbano), al amparo del Reglamento de Bienes y Servicios del Municipio de Tijuana (Ayuntamiento de Tijuana, 2002).

Sin embargo, casi todos los planes y programas a nivel regional y municipal reconocen el déficit de áreas verdes existente y algunos proponen estrategias para tratar de aumentar su número y superficie, e inclusive algunos asocian su localización con las áreas de riesgo de pendientes pronunciadas y sobre cursos de agua, y proponen conservar espacios con características ecológicas especiales.

\section{Discusión}

Según el modelo matriz-fragmento-corredor de Forman y Gordon (1986) y la teoría de la percolación, los paisajes que han perdido $60 \%$ de vegetación natural tienen graves problemas de fragmentación y disminución de la conectividad (O’Neill, Gardner y Turner, 1992). En la zMTTR, las coberturas naturales cubren $51 \%$ de su superficie, por lo que es imprescindible la planeación de áreas verdes antes de que se pierdan por urbanización.

Las áreas que se consideran en los escenarios son espacios de oportunidad que pueden aprovecharse para planear áreas verdes conectadas físicamente, que permitirían mantener cierto grado de conectividad del paisaje y aumentar la capacidad de resiliencia ante disturbios naturales y antrópicos que provean múltiples funciones (Ahern, 2007).

En el primer escenario, al conservar la vegetación natural en áreas de riesgo, se lograría mantener más de un tercio de la vegetación actual y todos los corredores naturales de los cursos de agua con vegetación riparia, indispensables para los aspectos hidrológicos, especialmente por la escasez de este recurso en la zona. Con ello se mejoraría el funcionamiento del paisaje ya que la vegetación trabaja como amortiguador para regular los flujos naturales, lo que podría disminuir los riesgos al estabilizar los suelos, reducir la cantidad y velocidad de la escorrentía pluvial, evitar inundaciones y deslaves y aumentar la infiltración de agua (Ahern, 2002; APA, 2013). Esto es particularmente importante para la zMTTR que ha sufrido de este tipo de problemas (Bocco et al., 1993). También regula el exceso de nutrientes o contaminantes en el agua, lo que evita que se dañen otros componentes del paisaje (Ahern, 2002), que pueden causar una baja de oxígeno en el agua y provocar la muerte de organismos de ríos y humedales y la proliferación de bacterias anaerobias o de algas nocivas (Chislock, 2013). Por ejemplo, la mayoría de los drenajes naturales y desviados de Tijuana desembocan en el estuario del Río Tijuana, que es una reserva de EE. uU. (Pezzoli et al., 2014), por lo que su conservación podría evitar posibles conflictos con el vecino país.

$\mathrm{Al}$ incluir las zonas con biodiversidad especial en el segundo escenario, la biodiversidad se conservaría mejor, debido al aumento de superficie del fragmento más grande y de la

\footnotetext{
2 Juegos infantiles para población $\geq 2500\left(1250,3500\right.$ y $\left.5500 \mathrm{~m}^{2}\right)$, jardín vecinal para población $\geq 5000(2$ 500,7000 y $\left.10000 \mathrm{~m}^{2}\right)$, parque de barrio $\geq 10000\left(11000,30800\right.$ y $\left.44000 \mathrm{~m}^{2}\right)$ y parque urbano para población $\geq 50000(9.1,18.272 .8$ y 18.2 ha).
} 
conectividad. Estas características aumentan en el tercer escenario con la adición del cinturón verde, que aunque dadas sus limitaciones de diseño, puede representar una guía para la planeación. Sobre el tamaño de los fragmentos se sabe que mientras más extensos sean, mayor será su capacidad para sostener poblaciones animales y vegetales más grandes y más diversas (Bennett y Saunders, 2010; Forman, 1995, Vila, Varga, Llausàs y Ribas, 2006). Desde el primer escenario, existe un fragmento de vegetación natural mayor de 10000 ha. Áreas con dimensiones y vegetación similares, que cerca del área de estudio, al sur de California, EE. UU., fueron identificadas por Crooks (2002) como de alta probabilidad de albergar lince o puma respectivamente. La presencia de grandes depredadores en un área es un indicador de la calidad del lugar (Escolástico, Abildo, R. Laramunt y T. Laramunt, 2013). Una de estas áreas es la parte de la Región Prioritaria (Conabio, 2012), y el gran fragmento entre Tijuana y Tecate, que por su extensión y biodiversidad podrían ser ANP a nivel estatal.

En todos los escenarios existen muchos fragmentos pequeños de vegetación natural que pueden ser utilizados por especies que necesitan de recursos de diferentes tipos de ecosistemas (Bennett y Saunders, 2010) y para moverse a través del paisaje. Estas áreas pueden ser usadas como lo que se conoce como stepping stones (Forman, 2008) o pequeños parques de barrio (Sedesol, 1999), que ayuden a conectar áreas más grandes de forma funcional, como por ejemplo las pequeñas áreas localizadas al oeste entre Tijuana y Rosarito, al sur de esta última o al este de Tecate.

Particularmente, convendría proteger y restaurar las áreas con vegetación natural que rodean a las presas, ya que su estado está relacionado directamente con la calidad y cantidad del agua de las presas, aspecto relevante debido a la escasez del recurso en la región (Gobierno del Estado de Baja California, 2013).

En términos de manejo, debido a que la vegetación de la zona de estudio está adaptada a un régimen natural de incendios (Lippitt et al., 2013), convendría aplicar técnicas como quemas controladas y clareo de material combustible, que junto con información a los pobladores puede ayudar a reducir este tipo de riesgo (Hurteau, Brayford, Fulé, Taylor y Martin, 2014). El Condado de San Diego (San Diego County, s. f.), además de ofrecer indicaciones sobre estas técnicas, recomienda las especies nativas que se deben promover y aquellas que deben estar más alejadas de las construcciones.

Cabe resaltar que no se hacen recomendaciones de manejo de pastizales, ya que en la zona de estudio, este tipo de uso de suelo ha sido identificado como un precursor de la urbanización (Farley et al., 2012), y no de desarrollo de actividades agropecuarias.

Desde el punto de vista legal, parte de la problemática para implementar iv radica en que las políticas urbanas y ambientales en México no están vinculadas. En la planeación territorial existe una disociación entre lo urbano y lo rural. Los Ordenamientos Ecológico Territoriales (OET) solo se aplican fuera de los centros de población, mientras que estos últimos, se regulan a través de los planes de desarrollo urbano (PDU) pero extendiéndose al área rural. De esta forma, la dicotomía urbano-ambiental produce distorsiones en la planeación territorial (Díaz y Ojeda-Revah, 2013). En el área de estudio, a pesar de tener la facultad, ninguno de los municipios ha elaborado un OET, dejando a los PDU delimitar las áreas de conservación. Asimismo, no existen mecanismos obligatorios de coordinación entre planes, porque en la práctica no se aplican los planes, por falta de capacidad, o ausencia de mecanismos institucionales o por intereses creados por los mercados de bienes raíces (Momm-Schult et al., 2013).

Las áreas de riesgo aunque mencionadas por leyes, planes y programas, en su mayoría no se especifican o no se respetan, en parte porque en el caso de Tijuana, más de la mitad del área urbana tiene origen irregular (Alegría y Ordoñez, 2005), pero también porque los municipios en busca de soluciones rápidas, construyen cerca de zonas 
inundables, cambian la topografía, canalizan arroyos y destruyen fragmentos naturales, lo que tiene consecuencias en el drenaje natural, obstruyendo ríos y arroyos y provocando inundaciones (Momm-Schult et al., 2013).

A pesar de que el estado y los municipios pueden crear ANP, en la zona de estudio no existe ninguna. Convendría declarar ANP a la zona prioritaria y como áreas de protección de biodiversidad a las zonas de biodiversidad especiales (Oberbauer, 1999) y al bosque de encinos, integrados como parte de la Iv.

Con respecto a las áreas verdes urbanas, al nivel federal solo se hacen recomendaciones de superficies por tamaño de población y se les visualiza únicamente como áreas de recreación y deporte (Sedesol, 1999). A nivel estatal, se determina 3\% del área vendible para la creación de áreas verdes solo para fraccionamientos y sin considerar la densidad de la población (Gobierno del Estado de Baja California, 1971). A nivel municipal, aunque mencionadas por casi todos los programas como mecanismo para reducir riesgos y conservar biodiversidad, a la fecha no se ha creado ninguna con éstos fines. Asimismo, no existe ninguna norma que obligue a los municipios a establecer un mínimo de área verde per cápita o de porcentaje urbano, que considere su accesibilidad equitativa o que establezca directrices para su desarrollo y mejora, y está permitido su cambio a otros usos.

La zMTTR tiene acceso al Fondo Metropolitano, recurso que proviene de la federación y que se asigna a programas, proyectos, obras de infraestructura u acciones en beneficio económico y social de las áreas metropolitanas (Secretaría de Hacienda y Crédito Público [SHCP], 2011). Con este fondo aparentemente desde el 2011, el gobierno del Estado impulsa tres proyectos metropolitanos: la Reserva Ecológica Metropolitana de Tijuana (20 ha), el Gran Parque Metropolitano de Playas de Rosarito y el Río Parque Tecate (Ayuntamiento de Playas de Rosarito, 2014, p.142). Sin embargo, a la fecha no se han reportado oficialmente avances en este tema.

\section{Conclusiones}

Los componentes del paisaje de la zMTTR están siendo fragmentados y aislados, lo que reduce su conectividad y por lo tanto su resiliencia ante disturbios. No obstante, existen espacios de oportunidad en la zMTTR que pueden ayudar a conservar la vegetación natural y mantener su conectividad física. Tan solo manteniendo las zonas de riesgo ampliadas a la distribución de vegetación riparia, se puede conservar buena parte de la vegetación natural con gran biodiversidad y endemismos, en forma de una red interconectada, confiriendo simultáneamente múltiples funciones y servicios ecosistémicos, como aumentar su umbral de resiliencia, reducir riesgos, aumentar el área verde por habitante e incluir la conservación de la biodiversidad.

Todos los escenarios de IV propuestos para la zMTTR se insertan en la legislación existente, sin embargo, el grado de factibilidad que cada uno tiene difiere. El primer escenario, sería posible tan solo reforzando el cumplimiento de la ley ya existente; mientras que para cristalizar el segundo escenario se requiere además voluntad política, ya que la declaratoria de ANP no es obligatoria para ningún nivel de gobierno. Por último, el tercer escenario es mucho menos factible, si se considera que existe una gran competencia por el suelo urbanizable.

En el escaso marco legal existente sobre áreas verdes urbanas, existen problemas de fragmentación espacial y sectorial en su diseño. Espacialmente, aunque contemplada por el marco legislativo, no existe una efectiva coordinación entre municipios, que permita la 
continuidad espacial de su diseño, agravada por la separación legal de la planeación urbana y rural dentro de cada municipio. De esta forma, a pesar de que la mayoría de los PDU y OET locales y regionales las consideran importantes y mencionan el rezago existente en su creación, pocos las relacionan con problemas de riesgos, ninguno las visualiza como un sistema conectado que aproveche al máximo los servicios ecosistémicos a escala de paisaje. Sectorialmente, su diseño no se integra con programas sociales, de salud, cultura, deporte, imagen urbana, etc., para aprovechar su capacidad multifuncional y reducir los costos de su mantenimiento. Inclusive la ley ampara el cambio de uso del suelo de las áreas verdes existentes y la falta de su aplicación y la ausencia de capacidades especializadas permite que sus condiciones de mantenimiento sean muy pobres.

Resulta entonces fundamental crear un marco legal integrado, que amplíe la visión de las áreas verdes urbanas a una que incluya a la vegetación natural, integrándolas en un sistema interconectado o IV, que aumente la capacidad de resiliencia del paisaje en el que se insertan las ciudades. Socialmente, esta nueva visión incluye el determinar de forma explícita un mínimo de áreas verdes por habitante, con una distribución equitativa para toda la población.

Futuras investigaciones sobre IV en la ZMTTR podrían profundizar en la distribución de la biodiversidad endémica o amenazada, y en la conectividad funcional de algunas especies clave para determinar corredores biológicos de forma más adecuada. Socialmente, la inclusión de la participación social en el diseño y mantenimiento de áreas verdes es un tema fundamental que debe ser explorado.

\section{Referencias}

Ahern, J. (2002). Greenways as strategic landscape planning: Theory and application. Estados Unidos: Wageningen Universiteit.

Ahern, J. (2007). Green infrastructure for cities : The spatial dimension. En V. Novotny y P. Brown (Eds.), Cities of the future: towards integrated sustainable water and landscape management (pp. 267-283). Londres, Inglaterra: IwA Publishing.

Ahern, J. (2013). Urban landscape sustainability and resilience: the promise and challenges of integrating ecology with urban planning and design. Landscape Ecology, 28(6), 1203-1212.

Alberti, M. y Marzluff, J. (2004). Ecological resilience in urban ecosystems: Linking urban patterns to human and ecological functions. Urban Ecosystems, 7(3), 241-265.

Alegría O. y Ordoñez, G. (2005). Legalizando la ciudad: asentamientos informales y procesos de regularización Tijuana. México: El Colegio de la Frontera Norte.

American Planning Association (APA). (2013). Análisis de características naturales. En Fundamentos de planificación de sitios (pp. 9-36). Estados Unidos: Autor.

Ayuntamiento de Playas de Rosarito. (26 de noviembre de 2010). Programa de desarrollo urbano del centro de población de Primo Tapia, Playas de Rosarito, Baja California. Periódico Oficial del Estado de Baja California, (tomo cxviıI, núm. 51). Recuperado de http://www.rosarito.gob.mx/rosaritov/transparencia/pdf/ProgramaDesarrolloUrbanoPrimoTapia.pdf

Ayuntamiento de Playas de Rosarito (9 de mayo de 2014). Plan Municipal de Desarrollo de Playas de Rosarito, Baja California 2014-2016. Periódico Oficial del Estado de Baja California (tomo cxxI, núm. 25). Recuperado de http://www.rosarito.gob. 
$\mathrm{mx} / \mathrm{VI} /$ WP-CONTENT/UPLOADS/2014/04/PLAN-MUNICIPAL-DE-DESARROLLO-DE-PLAYAS-DE-ROSARITO-BC-2014-2016.PDF

Ayuntamiento de Tecate. (24 de octubre de 2003). Programa de desarrollo urbano del centro de población de Tecate, Baja California. Periódico Oficial del Estado de Baja California, (tomo cx, núm. 48), pp. 2-122.

Ayuntamiento de Tecate. (2011). Plan Municipal de Desarrollo de Tecate 2011-2013. México: Autor.

Ayuntamiento de Tijuana. (8 de marzo de 2002). Reglamento de Bienes y Servicios del Municipio de Tijuana. Periódico Oficial del Estado de Baja California, (tomo cIx, núm. 10). Recuperado de http://www.tijuana.gob.mx/Reglamentos/pdf/REGLAMENTO\% 20DE\% 20BIENES\%20Y\%20SERVICIOS\% 20DEL\%20MUNICIPIO\%20 DE\% 20TIJUANA\% 20B.pdf

Ayuntamiento de Tijuana. (28 de noviembre de 2008). Programa parcial de desarrollo urbano del Valle de las Palmas. Periódico Oficial del Estado de Baja California, (tomo cXv, núm. 59, sección I), pp. 2-16.

Ayuntamiento de Tijuana. (3 de septiembre de 2010a). Programa de desarrollo urbano del centro de población de Tijuana, Baja California 2008-2030. Periódico Oficial del Estado de Baja California, (tomo cxviı, núm. 38, sección II), pp. 2-416.

Ayuntamiento de Tijuana. (3 de septiembre de 2010b). Reglamento de zonificación y usos del suelo del centro de población de Tijuana, Baja California. Periódico Oficial del Estado de Baja California, (tomo cxviI, núm. 38). Recuperado de http:// www.bajacalifornia.gob.mx/portal/gobierno/legislacion/periodico/2010/ SECC-I-03-09-2010.pdf

Balvanera, P. y Cotler, H. (2011). Los servicios ecosistémicos. Biodiversitas, (94), 7-11.

Beier, P., Penrod, K., Luke, C., Spencer, W. y Cabañero, C. (2006). South coast missing linkages: Restoring connectivity to wildlands in the largest metropolitan area in the United States. En K. Crooksy y M. Sanjayan (Eds.), Connectivity conservation (pp. 555-586). Reino Unido: Cambridge University Press.

Benedict, M. y McMahon, T. (2006). Green infraestructure. Linking landscape and communities. Estados Unidos: Island press.

Bennett, A. y Saunders, D. (2010). Habitat fragmentation and landscape change. En N. S. Sodhi y P. R. Ehrlich (Eds.), Conservation biology for all (pp. 88-106). Estados Unidos: Oxford University.

Bocco, G., Sánchez, R. y Riemann, H. (1993). Evaluación del impacto de las inundaciones en Tijuana (enero de 1993). Uso integrado de percepción remota y sistemas de información geografíca. Frontera Norte, 5(10), 53-83.

Bringas, N. y Sánchez, R. (2006). Social vulnerability and disaster risk in Tijuana: preliminary findings. En J. Clough-Riquelme y N. Bringas (Eds.), Equidity and sustainable development. Reflexions from the U.S.-México border (pp. 149-173). Estados Unidos: University of California.

Chislock, M. (2013). Eutrophication: causes, consequences and controls in aquati ecosystems. Nature Education Knowledge, 4(4), 10.

Colding, J. (2007). Ecological land-use complementation' for building resilience in urban ecosystems. Landscape and Urban Planning, 81(1-2), 46-55.

Comisión Nacional para Conocimiento y Uso de la Biodiversidad (Conabio). (2012). Portal de Geo-información. Sistema Nacional de Información sobre Biodiversidad. Recuperado de http://www.conabio.gob.mx/informacion/gis/ 
Crooks, K. (2002). Relative sensitivities of mammalian carnivores to habitat fragmentation. Conservation Biology, 16(2), 488-502.

Defries, R., Foley, J. y Asner, G. (2004). Land-use choices: balancing human needs and ecosystem function. The Ecological Society of America, 2(5), 249-257.

Díaz, D. y Ojeda-Revah, L. (2013). La reserva de la Biosfera Alto Golfo de California y Delta del Río Colorado: planeación territorial. Región y Sociedad, 25(58), 57-85.

Escolástico, C., Abildo, M., Laramunt, R. y Laramunt, T. (2013). Ecología I. Introducción. Organismos y poblaciones. Madrid, España: Universidad Nacional de Educación a Distancia.

Estación de Recepción México (ermex). (31 de diciembre de 2012). México: Secretaría de Agricultura, Ganadería, Desarrollo Rural, Pesca y Alimentación, Servicio de Información Agroalimentaria y Pesquera.

Estación de Recepción México (ermex). (31 de enero de 2013). México: Secretaría de Agricultura, Ganadería, Desarrollo Rural, Pesca y Alimentación, Servicio de Información Agroalimentaria y Pesquera.

Farley, K., Ojeda-Revah, L., Atkinson, E. y Eaton-González, B. (2012). Changes in land use, land tenure and landscape fragmentation in the Tijuana River watershed following reform of the ejido sector. Land Use Policy, 29(1), 187-197.

Flores, A., Pickett, T., Wayne, Z., Pouyat, R. y Pirani, R. (1998). Adopting a modern ecological view of the metropolitan landscape: the case of a greenspace system for the New York City region. Landscape and Urban Planning, 39(4), 295-308.

Food and Agriculture Organization of the United Nations (FAO). (2001). Lecture notes on the major soils of the world. Roma, Italia: Autor.

Forman, R. (1995). Land mosaics: The ecology of landscapes and regions. Reino Unido: Cambridge.

Forman, R. (2008). Urban regions: Ecology and planning beyond the city. Reino Unido: Cambridge University Press.

Forman, R. y Godron, M. (1986). Landscape ecology. Nueva York: John Wiley \& Sons.

Ganster, P. (2002). Tecate sus desafios en el siglo xxi. En P. Ganster, F. Cuamea, J. Castro y A. Villegas (Comps.), Tecate, Baja California: Realidades y desafíos de una comunidad mexicana fronteriza (pp. 251-267). México: San Diego State University Press.

García, E. (2004). Modificaciones al sistema de clasificación climática de Köppen. México: Offset Larios.

Gobierno del Estado de Baja California. (10 de abril de 1971). Reglamento de fraccionamientos del Estado de Baja California. Periódico Oficial del Estado de Baja California, (tomo LXXviII, núm. 1, sección I), pp. 1-34.

Gobierno del Estado de Baja California. (24 de junio de 1994). Ley de desarrollo urbano del Estado de Baja California. Periódico Oficial del Estado de Baja California, (tomo CI, núm. 26, sección I). (Última reforma 2 de agosto de 2013). Recuperado de http://www.congresobc.gob.mx/legislacion/Parlamentarias/TomosPDF/Leyes/ TOMO_VII/LEYDESUR_02AGO2013.pdf.

Gobierno del Estado de Baja California. (30 de noviembre de 2001a). Ley de protección al ambiente para el Estado de Baja California, México. Periódico Oficial del Estado de Baja California, (tomo CVIII, núm. 53, sección I), pp. 1-76.

Gobierno del Estado de Baja California. (16 de noviembre de 2001b). Programa regional de desarrollo turístico y ecológico del Corredor Costero Tijuana-Rosarito Ensenada Cocotren. Periódico Oficial del Estado de Baja California, (tomo cviII, núm. 50, sección I), pp. 2-160. 
Gobierno del Estado de Baja California. (12 de marzo de 2004). Declaratoria de zona conurbada Tijuana-Tecate-Rosarito. Periódico Oficial del Estado de Baja California, (tomo CXI, núm. 12), pp. 2-4.

Gobierno del Estado de Baja California. (2012). Programa de ordenamiento Zona Metropolitana Tijuana-Tecate-Playas de Rosarito-Ensenada. Recuperado de http:/ /www.sidue.gob. $\mathrm{mx} /$ doctos/2014/ot/ZM_TTPRE.pdf

Gobierno del estado de Baja California. (2013). Hidrología: Regiones hidrológicas. Recuperado de http://www.bajacalifornia.gob.mx/portal/nuestro_estado/recursos/hidrologia.jsp

Holling, C. y Gunderson, L. (2002). Resilience and adaptive cycles. En L. Gunderson y C. Holling (Eds.), Panarchy: understanding transformations in human and natural systems (pp. 25 -62). Estados Unidos: Island Press.

Huizar, H. y Ojeda-Revah, L. (2014). Los parques de Tijuana: una perspectiva de justicia ambiental. En L. Ojeda-Revah y I. Espejel (Coords.), Cuando las áreas verdes se transforman en paisaje. La visión de Baja California (pp. 87-120). México: Colegio de la Frontera Norte.

Hurteau, M., Bradford, J., Fulé, P., Taylor, A. y Martin, K. (2014). Climate change, fire management, and ecological services in the southwestern us. Forest Ecology and Management, 327, 280-289.

Instituto Municipal de Planeación (Implan). (2012). Plan Estratégico Metropolitano 20122034. Recuperado de http://www.cdt.org.mx/portals/2/documentos/pem2034/ Revista_PEM.pdf

Instituto Nacional de Estadística Geografía e Informática (Inegi) (1995). Anuario Estadístico. Baja California. México: Autor.

Instituto Nacional de Estadística Geografía e Informática (Inegi). (2004). Guía para la interpretación de cartografía: Edafología. México: Autor.

Instituto Nacional de Estadística Geografía e Informática (Inegi). (2010). Cuaderno estadístico del estado de Baja California. México: Autor.

Instituto Nacional de Estadística Geografía e Informática (Inegi). (2013). Mujeres y hombres en México 2012. México: Autor.

Instituto Nacional de Estadística Geografía e Informática (Inegi). (2014). Modelos digitales de elevación. Recuperado de http://www3.inegi.org.mx/sistemas/productos $/$ default.aspx? $\mathrm{c}=265 \& \mathrm{upc}=0 \& \mathrm{~s}=\mathrm{est} \& \mathrm{tg}=1007 \& \mathrm{f}=2 \& \mathrm{cl}=0 \& \mathrm{pf}=\mathrm{prod} \& \mathrm{ef}=0 \& \mathrm{c}-$ $\mathrm{t}=209000000$ \&.pg $=2$

Lippitt, C., Stow, D., O’Leary, J. y Franklin, J. (2013). Influence of short-interval fire occurrence on post-fire recovery of fire-prone shrublands in California, usa. International Journal of Wildland Fire, 22(2), 184-93.

McGarigal, K. (2006). Landscape pattern. En A. El-Shaarawi y W. Piegorsch (Eds.), Encyclopedia of Envirometrics (pp. 1441-1451). Nueva York: John Wiley \& Sons.

McGarigal, K., Cushman, S. y Ene, E. (2012). FRAGSTATS v4: Spatial Pattern Analysis Program for Categorical and Continuous Maps. Recuperado de http://www.umass.edu/lande$\mathrm{co} /$ research/fragstats/fragstats.html

McKinney, M. (2002). Urbanization, biodiversity and conservation. Bioscience, 52(10), 883890.

Mendoza, G., Acosta, G. y Vázquez, S. (2009). Estudio para la identificación de la microzonación sísmica en la colonia "Ampliación ejido plan libertador". México: Gobierno del Estado de Baja California. 
Momm-Schult, S., Piper, J., Denaldi, R., Freitas, S., Fonseca, M. y Oliveira, V. (2013). Integration of urban and environmental policies in the metropolitan area of São Paulo and in Greater London: the value of establishing and protecting green open spaces. International Journal of Urban Sustainable Development, 5(1), 89-104.

Moreno, O. (2013). Paisajes resilientes. Reflexiones en torno a la reconstrucción de territorios desde el manejo y diseño de infraestructuras verdes, en el marco de las estrategias de gestión de riesgo ante desastres. Nadir: Revista Electrónica de Geografía Austral, (1), 1-19.

Myers, N., Mittermeier, R., Mittermeier, C., Fonseca, G. da y Kent, J. (2000). Biodiversity hotspots for conservation priorities. Nature, 403(6772), 853-858.

Ndubisi, F. (2002). Managing change in the landscape: a synthesis of approaches for ecological planning. Landscape Journal, 21(1), 138-155.

Nyström, M. y Folke, C. (2001). Spatial resilience of coral reefs. Ecosystems, 4(5), 406-417.

O’Neill, R., Gardner, R. y Turner, M. (1992). A hierarchical neutral model for landscape analysis. Landscape Ecology, 7(1), 55-61.

Oberbauer, T. (1999). La vegetación del noroeste de Baja California. Fremontia, (edición especial), 16-22.

Ojeda-Revah, L. (1999). Land use and the conservation of natural resources in the Tijuana River basin. En H. Laurence (Ed.), Shared space: rethinking the U.S.-Mexico border environment (pp. 211-232). San Diego, Estados Unidos: University of California.

Pauchard, A., Aguayo, M. y Alaback, P. (2006). Cuantificando la fragmentación del paisaje: las métricas y sus significados ecológicos. En A. Grez, J. Simonetti y R. Bustamante, Biodiversidad en ambientes fragmentados de Chile: patrones y procesos a diferentes escalas, Santiago (Eds.), (pp. 41-66). Chile: Universitaria.

Pezzoli, K., Kozo, J., Ferran, K., Wooten, W., Rangel, G. y Al-Delaimy, W. K. (2014). One bioregion/one health: An integrative narrative for transboundary planning along the US-Mexico border. Global Society, 28(4), 419-440.

Pickett, S., Cadenasso, M. y Grove, J. (2004). Resilient cities: meaning, models and metaphor for integrating the ecological, socio-economic and planning realms. Landscape and Urban Planning, (69), 369-384.

Puente, S. (1996). Vulnerabilidad urbana y desarrollo sustentable. En J. Calva, B. Palomino y J. Navarro (Coords.), Sustentabilidad y desarrollo ambiental (tomo II, pp. 61-70). México: Juan Pablos Editor.

Riemann, H. y Ezcurra, E. (2007). Endemic regions of the vascular flora of the peninsula of Baja California, Mexico. Journal of Vegetation Science, 18(3), 327-336.

San Diego County. (s. f). Fire, defensible space, and you. Recuperado de http://www.sandiegocounty.gov/pds/fire_resistant.html

San Diego Environmental Mitigation Program Working Group (sANDAG). (2011). APPENDIX 2 Selected corridor, connectivity and linkage references from the MSCP, MHCP and associated documents relevant to the Connectivity Monitoring Strategic Plan. En Connectivity Monitoring Strategic Plan for the San Diego Preserve System. San Diego Management Monitoring Program. Recuperado de http://www.sdmmp.com/Libraries/ Strategic_Plans/CMSP_Appendix2_01112011.sflb.ashx

Sánchez-Rodríguez, R. (2011). Urban and social vulnerability to climate variability in Tijuana, Mexico. En R. Kasperson y M. Berberian (Eds.), Integrating science and policy. Vulnerability and resilience in Global Environmental Change (pp. 187-214.). Nueva York: Earthscan. 
Schneider, A., Friedl, M. y Potere, D. (2009). A new map of global urban extent from MoDIS satellite data. Environmnetal Research Letters, 4(4), 1-11.

Secretaría de Agricultura y Recursos Hidráulicos (SARH). (1 de diciembre de 1992). Ley de Aguas Nacionales. Diario Oficial de la Federación, (tomo CQLXXI, núm. 1). (Última reforma 11 de agosto de 2014). Recuperado de http://www.diputados.gob.mx/ LeyesBiblio/ref/lan/LAN_orig_01dic92_ima.pdf

Secretaría de Desarrollo Social (Sedesol). (21 de julio de 1993). Ley General de Asentamientos Humanos. Diario Oficial de la Federación (tomo cDlxxviı, núm. 15). (Última reforma en 2014). Recuperado de http://www.diputados.gob.mx/LeyesBiblio/pdf/133.pdf

Secretaría de Desarrollo Social (Sedesol). (1999). Sistema normativo de equipamiento urbano. Tomo v. Recreación y Deporte. Recuperado de http:// www.inapam.gob.mx/work/models/SEDESOL/Resource/1592/1/images/recreacion_y_deporte.pdf

Secretaría de Hacienda y Crédito Público (shCP). (11 de abril de 2011). Acuerdo por el que se emiten las reglas de operación del fondo metropolitano. Diario Oficial de la Federación, (tomo DCXai, núm. 7, Primera Sección). Recuperado de http://www. hacienda.gob.mx/EGRESOS/PEF/temas_gasto_federalizado/fondo_metropolitano/reglas_operacion_FM_2011.pdf

Secretaría de Medio Ambiente y Recursos Naturales y Pesca (Semarnap). (28 de enero de 1988). Ley General del Equilibrio Ecológico y la Protección al Ambiente. Diario Oficial de la Federación, (tomo cDxII, núm.19). (Última reforma 16 de enero de 2014). Recuperado de http://biblioteca.semarnat.gob.mx/janium/Documentos/ Ciga/agenda/DOFsr/148.pdf

Secretaría de Medio Ambiente y Recursos Naturales (Semarnat). (2012). Suelos. Informe de la situación del medio ambiente en México: compendio de estadísticas ambientales, indicadores clave y de desempeño ambiental (pp. 119-148). México: Autor.

Sierra, O. (2002). Cultura, recreación y deporte en Tecate. En P. Ganster, F. Cuamea, J. Castro, y A. Villegas (Comps.), Tecate, Baja California: Realidades y desafios de una comunidad mexicana fronteriza (pp. 99-105). México: San Diego State University Press.

Strahler, A. (1957). Quantitative analysis of watershed geomorphology. Eos Transactios American Geophysical Union, 38(6), 913920.

Tzoulas, K., Korpela, K., Venn, S., Yli-Pelkonen, V., Kazmierczak, A., Niemela, J. y James, P. (2007). Promoting ecosystem and human health in urban areas using green infrastructure: A literature review. Landscape and Urban Planning, 81(3), 167-178.

Venegas, F. y Rojas, R. (2009). Teoría y práctica del ordenamiento y manejo sustentable del territorio: Tijuana-Rosarito-Tecate, Baja California, México. Información Tecnológica, 20(3), 73-88.

Vila, J., Varga, D., Llausàs, A. y Ribas, A. (2006). Conceptos y métodos fundamentales en ecología del paisaje (Landscape ecology). Una interpretación de la geografía. Documents d'Anàlisi Geogràfica, (48), 151-166.

Whitford, V., Ennos, A. y Handley, J. (2001). City form and natural process: indicators for the ecological performance of urban areas and their application to Merseyside, UK. Landscape and Urban Planning, 57(2), 91-103.

Wilby, R. y Perry, G. (2006). Climate change, biodiversity and the urban environment: a critical review based on London, Uk. Prog. Phys. Geography, 30(1), 73-98.

Wolch, J. (1996). Zoöpolis. Capitalism Nature and Socialism, 7(2), 21-47.

$\mathrm{Wu}, \mathrm{J}$. (2008). Making the case for landscape ecology: an effective approach to urban sustainability. Landscape Journal, (27), 41-50. 
Jazmín Ochoa González

Mexicana. Maestra en Administración Integral del Ambiente, licenciada en Biología por la Universidad de Guadalajara, adscrita a El Colegio de la Frontera Norte en el Departamento de Estudios Urbanos y del Medio Ambiente. Línea de investigación: Ecología del paisaje.

Lina Ojeda-Revah

Mexicana. Doctora, adscrita a El Colegio de la Frontera Norte, Departamento de Estudios Urbanos y del Medio Ambiente. Líneas de investigación: ecología del paisaje e infraestructura verde. Publicación reciente: Cuando las áreas verdes se transforman en paisaje. La visión de Baja California (2014), en colaboración con Ileana Espejel, El Colegio de la Frontera Norte. IsBN: 978-607-479-144-0. 